\title{
ANÁLISE DA PESCA DA PESCADA-FOGUETE NA COSTA CENTRO-SUL DO BRASIL
}

(Recebido em 24/2/1965)

\author{
N. Yamaguti \\ A. E. D. de Moraes \\ Instituto Oceanográfico da Universidade de São Paulo \\ Departamento da Produção Animal da Secretaria da Agricultura
}

\section{SYNOPSIS}

In this paper data on catch and effort by gear are analysed, for weakfish (Macrodon ancylodon) landed at Santos from January 1959 to December 1963. The region studied was a narrow band about 30 nautical miles wide, along the southern coast of Brazil, between $23^{\circ} \mathrm{S}$ and $34^{\circ} \mathrm{S}$.

From the analysis of monthly data of production per unit-effort by -squares of $1^{\circ}$ on a side, we divided the studied region in two areas: area I (from $23^{\circ} \mathrm{S}$ to $27^{\circ} \mathrm{S}$ ) and area II (from $28^{\circ} \mathrm{S}$ to $34^{\circ} \mathrm{S}$ ). The index of unit-effort production and the effort concentration index were computed grouping the data by quarters.

From the results we may drow the following conclusions:

1 - In a general way, the effort for catch weak-fish has been applied satisfactorily because the medium and large parejas have operated almost in areas with average density on higher than average density;

2 - The production per unit-effort in the area $I$ is smaller than the production in area II, which suggests that the index of abundance is higher in area II;

3 - The decrease in production per unit-effort, in area II, suggests a decrease in the abundance or availability of weak-fish in this area;

4 - In the area I, the index of production per unit-effort remained approximately at the same level.

\section{INTRODUÇÃO}

Neste trabalho são apresentados os resultados da análise dos índices de produção da pescada-foguete por unidade de esfôrço e dos índices de concentração’de esfôrço; a finalidade foi determinar

Publ. n० 218 do Inst. Ocean. da USP. 
se o estoque de pescada-foguete está sendo afetado pela pesca e também se a frota pesqueira está aplicando devidamente o seu esfôrço na captura dessa espécie.

\section{MATERIAL E MÉTODOS}

Foram analisados os dados de desembarque de pescada-foguete em Santos, coletados durante o período de janeiro de 1959 a dezembro de 1963, e do esfôrço aplicado na sua captura pelos barcos que operam entre as latitudes $23^{\circ} \mathrm{S}$ e $34^{\circ} \mathrm{S}$, dentro do limite de cêrca de 30 milhas náuticas da costa.

Para a classificação dos barcos e dos aparelhos foi usado o mesmo critério utilizado por Vazzoler \& Sá (1963), de acôrdo com Braga (1961) e Richardson \& Santos (1962), dividindo os barcos nas seguintes categorias: frota estrangeira - "trawlers" de parelhas grandes (TPG) ; frota nacional - "trawlers" de parelhas médias e grandes (TPMG), pequenas (TPP), "trawlers" de portas médios e grandes (TPoMG) e pequenos (TPoP).

Como os barcos empregam rêdes de arrastão foi usado como unidade de esfôrço a hora-lance, para a obtenção da produção por unidade de esfôrço ( $\mathrm{kg} /$ hora-lance), e para comparação das diversas áreas da costa, esta foi dividida em blocos de $1^{\circ}$ de lado, segundo suas coordenadas (Richardson \& Moraes, 1960).

Pela análise das variações mensais dos índices de produção por unidade de esfôrço por bloco, para os diversos tipos de aparelhos, pudemos dividir a região estudada em duas áreas: área I — da latitude $23^{\circ} \mathrm{S}$ a $28^{\circ} \mathrm{S}$ e área II — de $28^{\circ} \mathrm{S}$ a $34^{\circ} \mathrm{S}$ (Fig. 1). Os dados das duas áreas foram analisados e agrupados trimestralmente.

$\mathrm{O}$ índice de densidade ponderado e não ponderado, e de concentração de esfôrço (Gulland, 1959) foi obtido pelo método utilizado por Vazzoler \& Sá (1963), embora nem todos os barcos dirijam seu esfôrço para a captura da pescada-foguete.

\section{RESULTADOS}

As produções anuais de pescada-foguete, em quilos, por categoria de barcos, e o esfôrço empregado, em horas, estão apresentados na Tabela I. Os TPG e TPMG foram os que apresentaram maiores produções, com médias de produção dos cinco anos, respectivamente de $61,5 \%$ e $29,0 \%$ da produção total. Foram seguidos pelos TPP com $7,0 \%$, TPoMG com $2,1 \%$ e TPoP com $0,4 \%$. A porcentagem média de pescada-foguete, em relação ao total do pescado, desembarcado pelos citados barcos, durante o período, incluindo os crustáceos, foi de $21,0 \%$. 
Nas variações trimestrais dos índices de produção por unidade de esfôrço por categoria de barco (Fig. 2), na área I, observamos que os TPP apresentaram tendência para aumentar as produções durante a época quente (I e IV trimestres), quando atingiram os máximos de produção, e a diminuir durante a época fria (II e III trimestres), quando ocorreram os mínimos de produção; os TPMG apresentaram tendência semelhante, com máximos de produção no I ou II e IV trimestres e com mínimos de produção no III trimestre. Os TPG aplicaram o seu esfôrço esporàdicamente nessa área, não nos permitindo a observação das variações de produção durante os trimestres. Os TPoP e TPoMG não estão representados nessa figura por apresentarem níveis de produção muito baixos

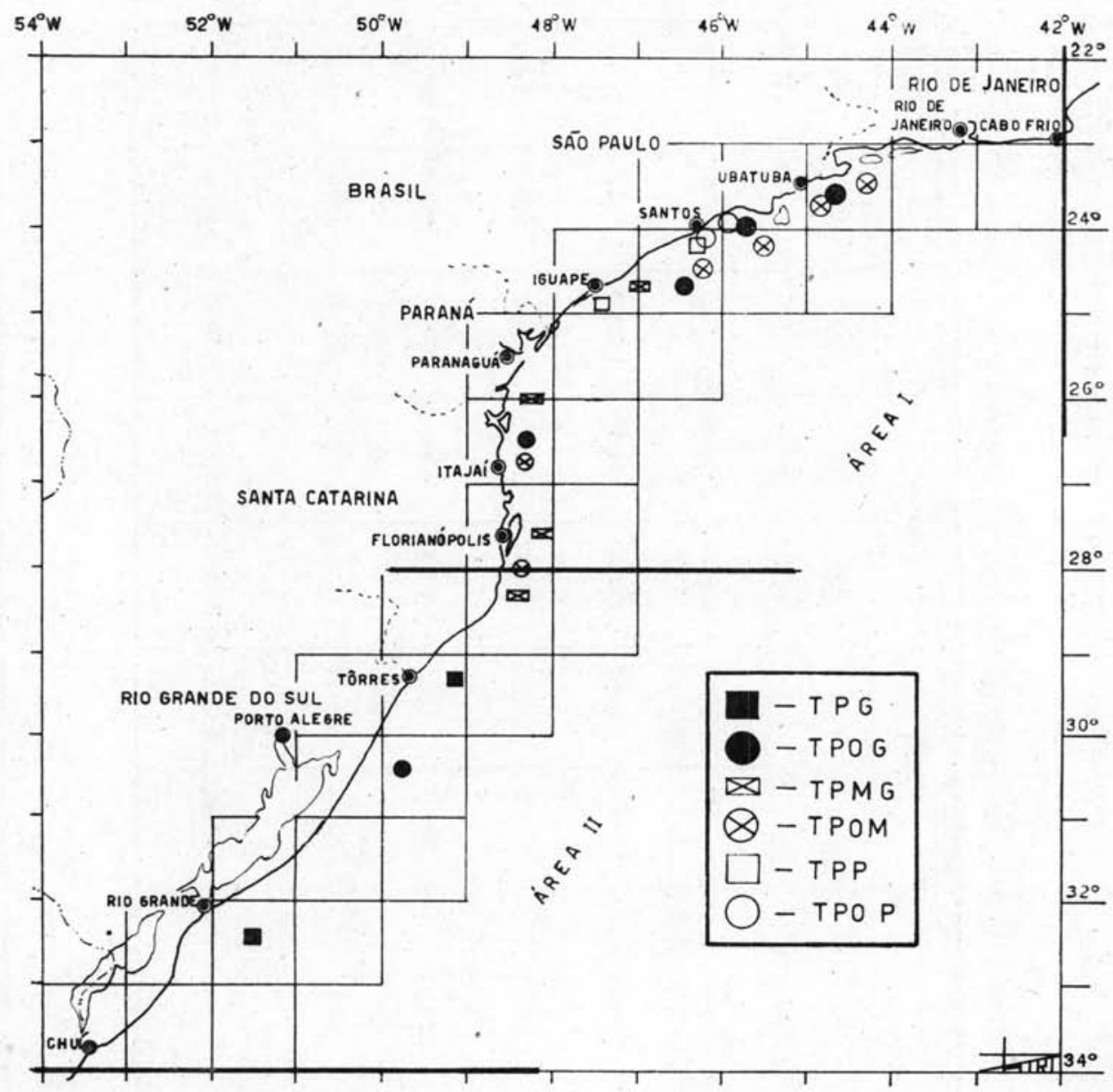

Fig. 1 - Áreas de pesca da peșcada-foguete. 


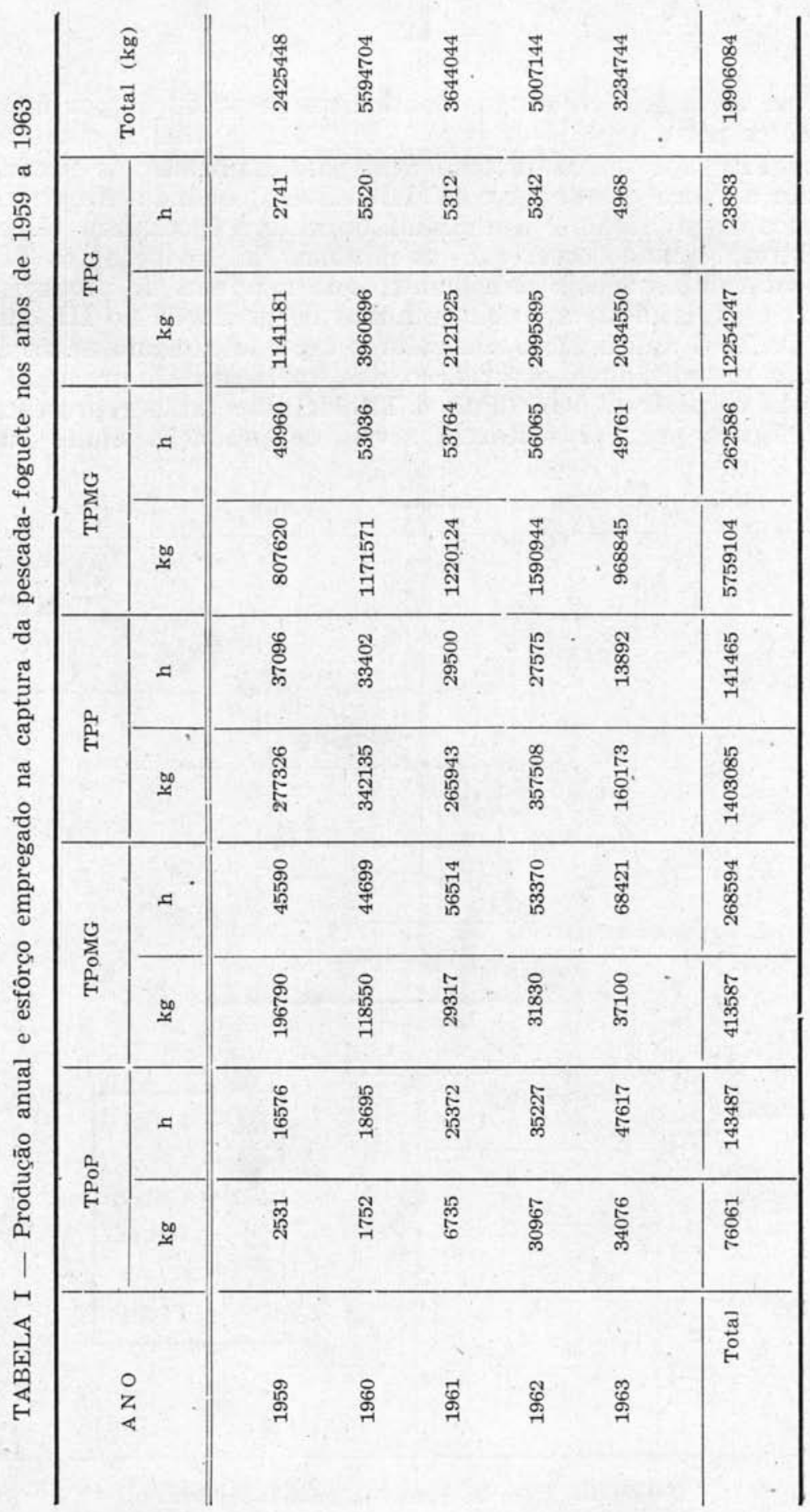




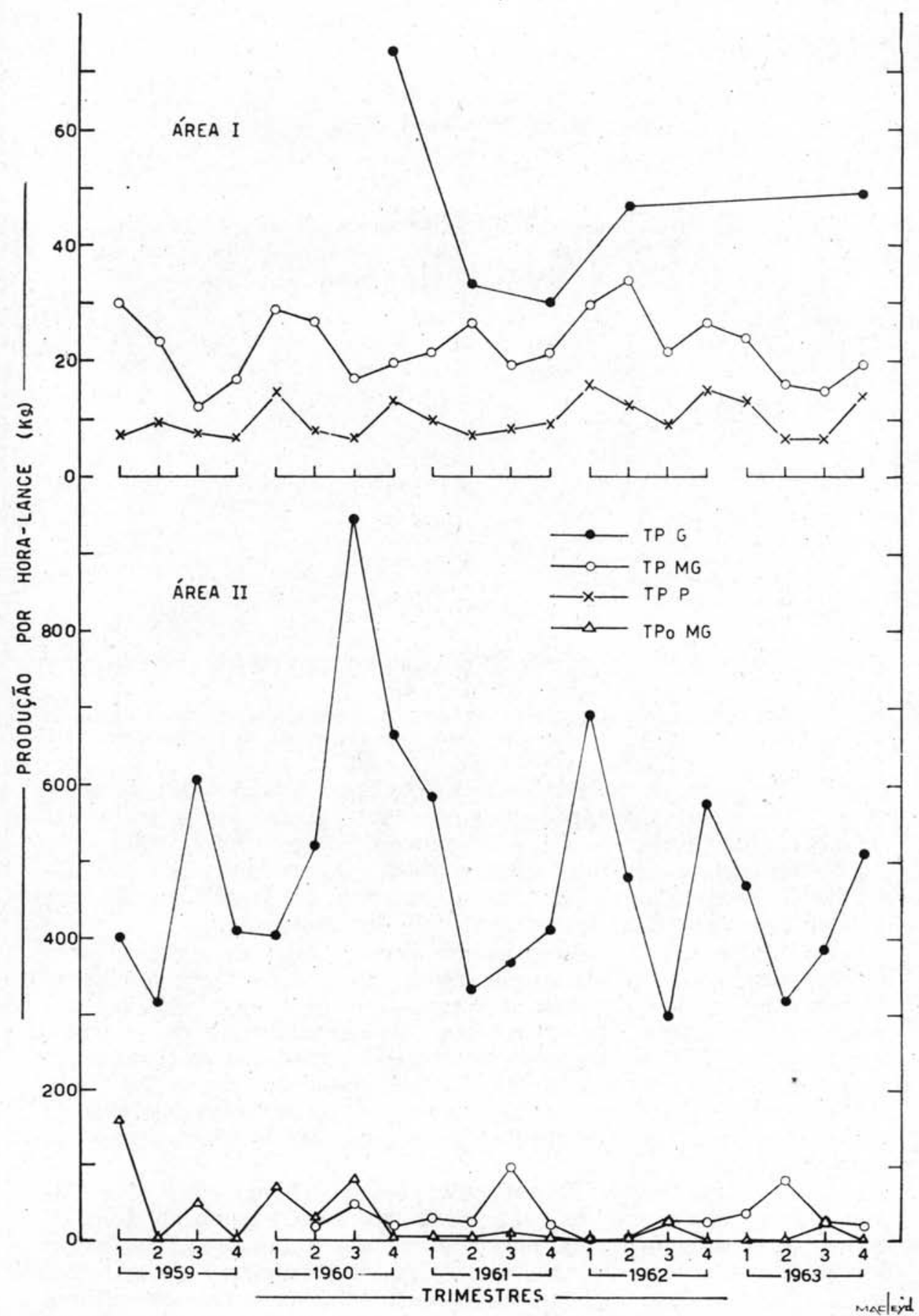

Fig. 2 - Variaçao trimestral da produção de pescada-foguete por hora-lance, para as diferentes categorias de barcos, por área, para o período de 1959 a 1963. 

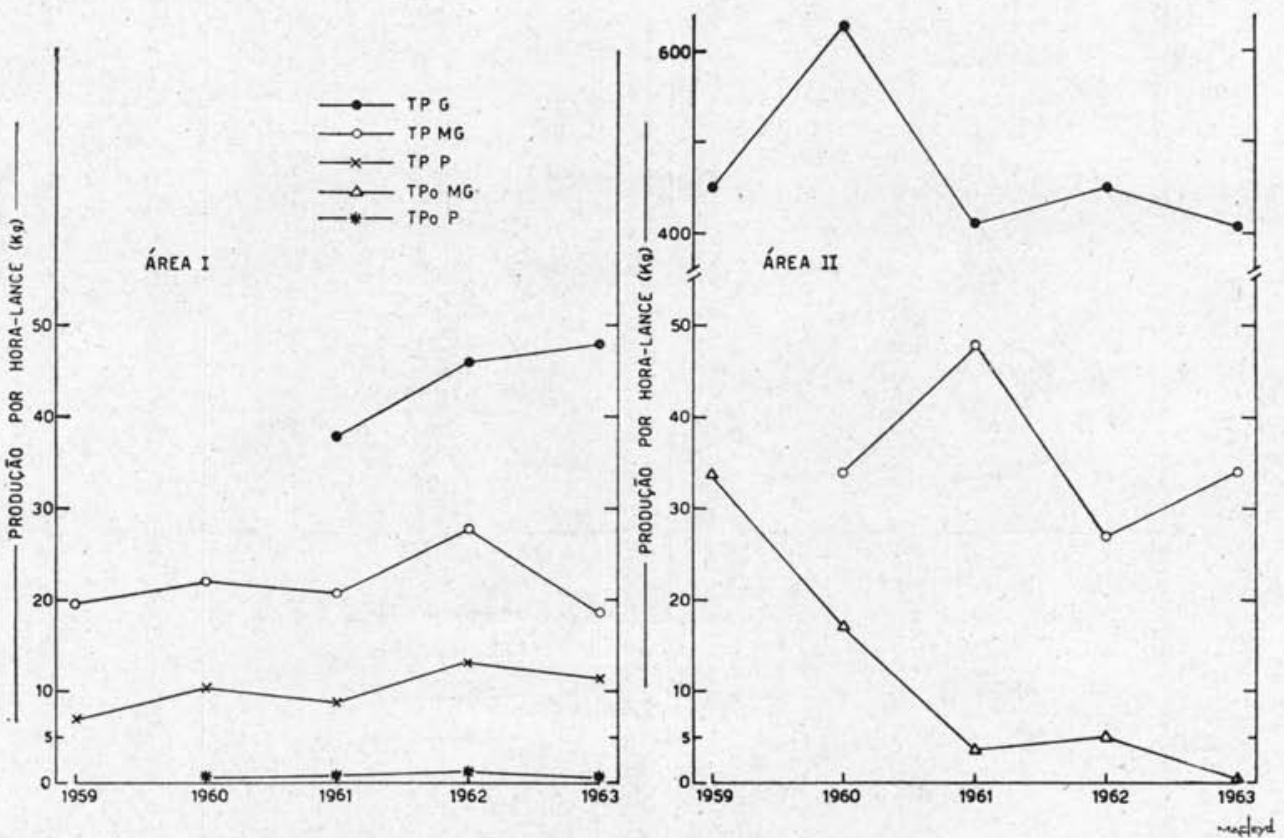

Fig. 3 - Variação anual da produção de pescada-foguete por hora-lance, para as diferentes categorias de barcos, por área, para o periodo de 1959 a 1963.

(médias trimestrais inferiores a $1,5 \mathrm{~kg}$ /hora-lance). Na área II, os TPG apresentaram produção mais elevada do que a frota nacional, com máximos no III e IV trimestres em 1959 e 1960 e no I e IV trimestres em 1961, 1962 e 1963. A produção dos TPoMG e TPMG, embora irregular, foi superior à da área I, sendo que os máximos ocorreram geralmente no III trimestre.

Os índices anuais de produção por unidade de esfôrço para as diversas categorias de barcos (Fig. 3) na área I apresentaram uma tendência à estabilidade, enquanto que na área II, houve uma tendência de queda. Os "trawlers" de parelha nas duas áreas, apresentaram índices de produção mais elevados que os "trawlers" de porta, sendo a produção dos TPMG maior do que a dos TPP. Comparando os índices de produção das duas áreas, notaremos que há uma grande diferença entre ambos, sendo muito mais elevados na área II.

Quanto aos índices de concentração de esfôrço (Fig. 4 e Tabela II), os "trawlers" de porta, tanto na área I como na área II, aplicaram seu esfôrço, na maior parte dos trimestres, em locais de densidade abaixo da média. Entre os "trawlers" de parelha, os TPP aplicaram, na área I, quase a totalidade do seu esfôrço em áreas de densidade abaixo da média; os TPMG, na área I, aplicaram a maior parte do seu esfôrço em locais com densidade 


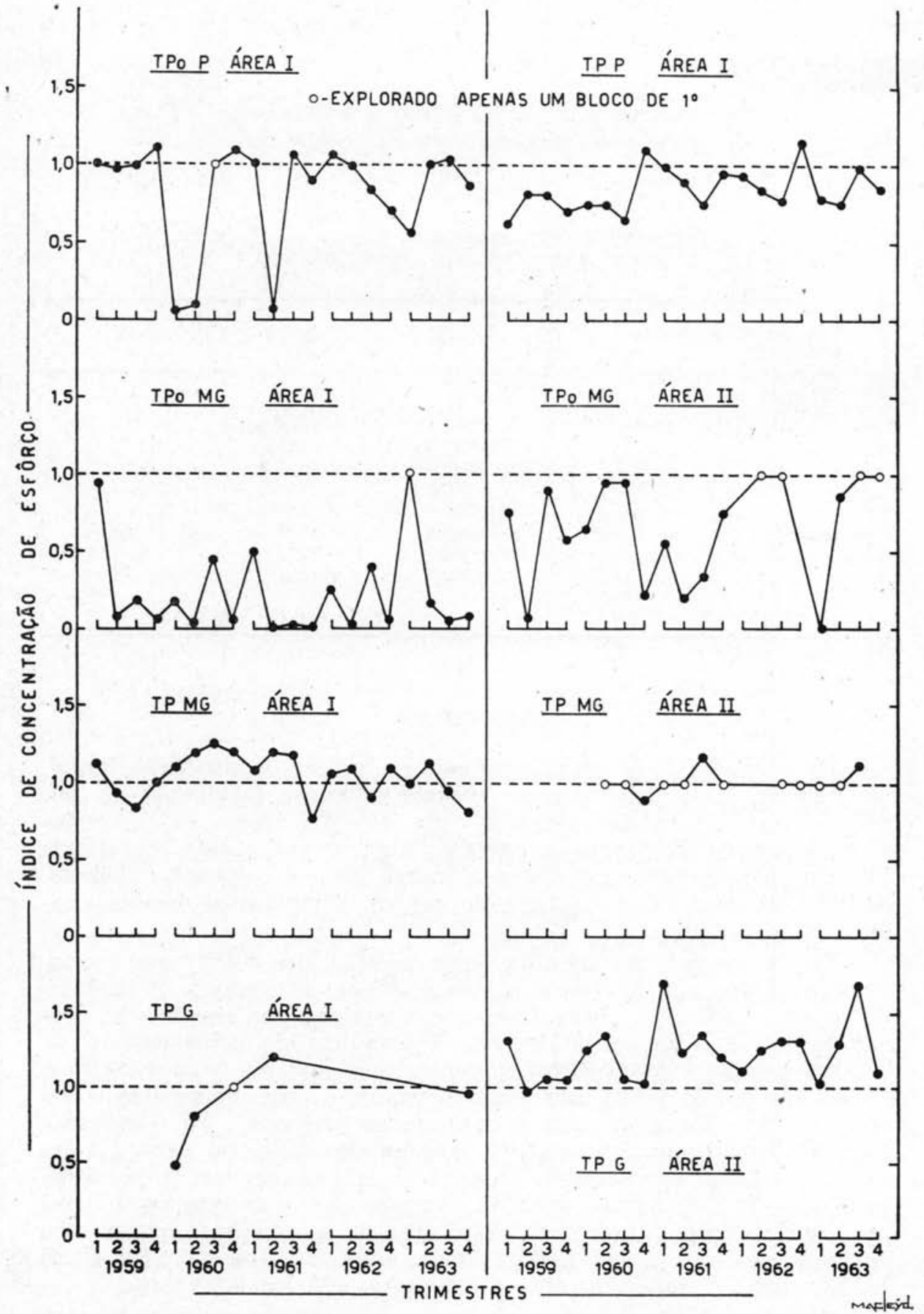

Fig. 4 - Valores trimestrais do indice de concentração de esfôrço, para a pesca da pescada-foguete, para as diferentes categorias de barcos, por área, para o período de 1959 a 1963. 
superior à média e na área II, próximo à média; os TPG, na área II, aplicaram quase todo seu esfôrço em locais com densidade sur. perior à média.

TABELA II - Número de trimestres com índice (I) de concentração de esfôrço menor, igual e maior que um

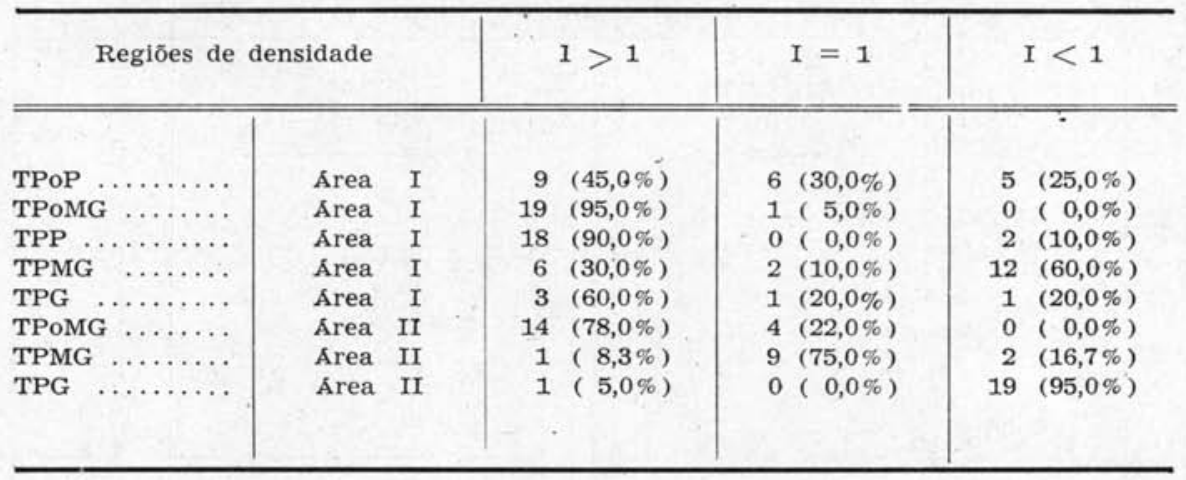

\section{DISCUSSÃO}

Os "trawlers" de porta apresentam índices de produção baixa, em relação à pescada, porque aplicam a quase totalidade de seu esfôrço na captura de camarões. Os TPoMG visam ao camarãorosa, pescando nas lages e parcéis; alguns, entretanto, capturam também peixes para completar a carga ou, em algumas viagens, dedicam-se sòmente à captura de peixes, dirigindo-se nessas ocasiões para a área II.

Os "trawlers" de parelha, com exceção dos TPP, que capturam camarões sete-barbas e peixes, dedicam-se sòmente à captura de peixes, aplicando quase todo o seu esfôrço em regiões de densidade média e acima da média. Os índices de concentração de esfôrço para a pescada-foguete, em relação àqueles para a corvina (Vazzoler \& Sá, 1963) são mais elevados, o que sugere que o esfôrço é mais dirigido para a captura da pescada. Se compararmos a produção por unidade de esfôrço dos TPG na área I e na área II, (embora tenha sido pequeno o esfôrço empregado por essa categoria de barcos na área I), vamos observar que os índices apresentam grande desnível. Na área I, as médias anuais não foram superiores a $48 \mathrm{~kg}$ /hora-lance, enquanto que na área II as médias anuais nunca foram inferiores a $400 \mathrm{~kg} /$ hora-lance.

$\mathrm{Na}$ área I houve pouca variação nas médias anuais de produção por hora-lance, talvez porque vem sendo explorada há longo tempo; enquanto na área II, que vem sendo explorada mais inten- 
samente só a partir de 1959, houve diminuição, sugerindo declínio do nível de abundância. Porém, devemos considerar que os dados dos primeiros trimestres de 1959 não representaram as possibilidades reais de captura, por ter sido início de pesca dos barcos estrangeiros e que nos últimos trimestres de 1960 os índices de produção foram elevados, talvez porque a pesca incidiu sôbre uma área com excepcional concentração de peixes. A grande queda de produção dos TPoMG não deve ser considerada, pois foi ocasionada pelo crescente desinterêsse dos pescadores, dêsse tipo de aparelho, pela captura de peixes.

\section{CONCLUSŌES}

Analisando os dados de desembarque, coletados desde janeiro de 1959 até dezembro de 1963, e o esfôrço aplicado na captura da pescada-foguete, dos barcos do pôrto de Santos que operaram entre as latitudes $23^{\circ} \mathrm{S}$ e $34^{\circ} \mathrm{S}$, nas águas costeiras da região centrosul do Brasil, chegamos às seguintes conclusões:

1 - De um modo geral, o esfôrço empregado para a captura da pescada-foguete vem sendo aplicado satisfatòriamente, uma vez que os TPMG ("trawlers" de parelhas médias e grandes - frota nacional) e TPG ("trawlers" de parelhas grandes frota estrangeira) aplicaram a maior parte do seu esfôrço em áreas de densidade média e acima da média.

2 - A produção por unidade de esfôrço na área I (de $23^{\circ} \mathrm{S}$ até $28^{\circ} \mathrm{S}$ ) é bem menor do que a produção na área II (de $28^{\circ} \mathrm{S}$ até $34^{\circ} \mathrm{S}$ ), sugerindo que o índice de abundância da pescada-foguete é maior na área II.

3 - A queda de produção por unidade de esfôrço sugere uma diminuição nos índices de abundância ou na disponibilidade da pescada-foguete na área II.

4 - Na área I, os índices de produção mantiveram-se aproxımadamente num mesmo nível.

B I B L I O G A F I A

Braga, A. DA S.

1961. Estudos sôbre o desenvolvimento da pesca maritima motorizada no Estado de São Paulo. Bolm Ind. anim., n.s., vol. 19, n. ${ }^{\circ}$ único, p. 33-49.

Gulland, J. A.

1959. A study of fish populations by the analysis of commercial catches. Rapp. P. - v. Réun. Commn int. Explor. scient. Mer Méditerr., vol. 140 , n. $^{\circ} 1$, Contr. n. ${ }^{\circ}$ 2, p. 21-29. 
Richardson, I. D. \& Moraes, M. N. DE

1960. A first appraisal of the landing and mechanism of the Santos fishery. Bolm Inst. oceanogr., S Paulo, vol. 11, n. ${ }^{\circ}$, p. 5-86.

Richardson, I. D. \& Santos, E. P. Dos

1962. Note on the selectivity of meshes used by Santos fishing fleet. Bolm Inst. oceanogr., S Paulo, vol. $12, \mathrm{n} .^{\circ} 1$, p. 33-35.

Vazzoler, A. E. A. DE M. \& SÁ, E. M. DE

1963. Análise da pesca da corvina na costa centro-sul do Brasil. Bolm Inst. oceanogr., S Paulo, vol. 13, n. $^{\circ} 2$, p. 61-72. 